\title{
Measuring and reporting quality of life outcomes in clinical trials in cystic fibrosis: a critical review Janice Abbott* and Anna Hart
}

\author{
Address: Faculty of Health, University of Central Lancashire, Preston, PR1 2HE, UK \\ Email: Janice Abbott* - jabbott@uclan.ac.uk; Anna Hart - ahart@uclan.ac.uk \\ * Corresponding author
}

This article is available from: http://www.hqlo.com/content/3/1/19

C) 2005 Abbott and Hart; licensee BioMed Central Ltd.

This is an Open Access article distributed under the terms of the Creative Commons Attribution License (http://creativecommons.org/licenses/by/2.0), which permits unrestricted use, distribution, and reproduction in any medium, provided the original work is properly cited.

\begin{abstract}
Good quality clinical trials are essential to inform the best cystic fibrosis (CF) management and care, by determining and comparing the effectiveness of new and existing therapies and drug delivery systems. The formal inclusion of quality of life (QoL) as an outcome measure in CF clinical trials is becoming more common. Both an appropriate QoL measure and sound methodology are required in order to draw valid inferences about treatments and QoL. A review was undertaken of randomised controlled trials in cystic fibrosis where QoL was measured. EMBASE, MEDLINE and ISI Web of Science were searched to locate all full papers in the English language reporting randomised controlled trials in cystic fibrosis, published between January 1991 and December 2004. All Cochrane reviews published before December 2004 were hand searched. Papers were included if the authors had reported that they had measured QoL or well being in the trial. 16 trials were identified. The interventions investigated were: antibiotics (4); home versus hospital administration of antibiotics (I); steroids (I); mucolytic therapies (6); exercise (3) and pancreatic enzymes (I). Not one trial evaluated in this review provided conclusive results concerning QoL. This review highlights many of the pitfalls of QoL measurement in CF clinical trials and provides constructive information concerning the design and reporting of trials measuring QoL.
\end{abstract}

\section{Review \\ Cystic fibrosis and its management}

Cystic fibrosis (CF) is a life threatening, recessively inherited disease caused by defects in a single gene on chromosome $7[1,2]$. The faulty gene causes an increased production of thickened secretions in most organs of the body. In the respiratory tract this impairs the clearance of micoorganisms resulting in recurrent infections, inflammation, lung damage and eventually death from respiratory failure. In the pancreas, the pancreatic exocrine cells become blocked, leading to the failure of the pancreas to produce digestive enzymes causing the maldigestion and malabsorption of nutrients. Current median survival is more than 30 years $[3,4]$, and half of children born in the 1990 's are expected to survive to more than 40 years [5]. With increasing age, however, a high proportion of people develop diabetes mellitus, and some patients endure a variety of complications including pneumothorax, haemoptysis, chronic liver disease and osteoporosis.

Cystic fibrosis has an extraordinarily demanding treatment regimen. The management of respiratory disease is directed at identifying and eradicating bacterial infection from the airways. Preventing chronic infection with Pseudomonas aeruginosa can slow down the deterioration in lung function and improve survival [6,7]. Respiratory 
disease is treated with antibiotics, mucolytics, bronchodilators and corticosteroids. Additionally, twice daily chest physiotherapy and an exercise regimen aid the clearance of respiratory secretions. The management of gastrointestinal symptoms hinges on the maintenance of body weight and, therefore, a high energy, high fat diet is prescribed. To aid the absorption of nutrients, oral pancreatic enzymes are taken with food. Malnutrition is managed with fat-soluble vitamins and oral feed supplements and/ or where required, nocturnal enteral feeding. CF-related diabetes requires insulin, and further therapies are required to deal with other complications.

\section{The importance of clinical trials in CF}

Effective treatments, in particular those that are acceptable to patients, are crucial to slow down disease progression. Good quality clinical trials are essential to generate evidence to inform CF management, by determining and comparing the effectiveness of therapies and drug delivery systems. Often, the ultimate aim of treatment is to increase survival, but it is impractical for trials involving younger patients to have survival as a primary end-point. Instead investigators opt for proxy outcome measures. The progression of CF disease is usually evaluated by changes in lung function; forced expiratory volume in 1 second $\left(\mathrm{FEV}_{1}\right)$ being the typical primary outcome measure. It has been commonplace for researchers to conclude that because treatments had benefits for clinical outcomes there must also have been benefits for QoL. There are many such assertions in the literature without empirical evidence, however, the formal inclusion of QoL as an outcome measure in CF clinical trials is now increasing.

\section{The quality of clinical trials}

There has been considerable concern about the quality of reporting of randomised controlled trials (RCTs). Poorlydesigned trials are likely to produce biased results and hence misinformed decision-making. Inadequate reporting means that readers are unable to assess the quality of the design of an RCT and are consequently unable to assess the usefulness of the conclusions. The CONSORT statement [8] was devised to improve the quality of reporting of RCTs. Both an appropriate QoL measure and sound methodology are required for valid inferences about treatments and QoL. With this in mind a review was undertaken of RCTs in cystic fibrosis where QoL was measured.

\section{The identification of papers}

EMBASE, MEDLINE and ISI Web of Science were searched to locate all full papers in the English language reporting RCTs in cystic fibrosis, published between January 1991 and December 2004. Papers were located that included 'cystic fibrosis' and 'quality of life' or 'health status' in the title, abstract or keywords, and these were hand-searched for all randomised controlled trials. Extra searches on 'well-being' were carried out in databases where this key word was accepted. Papers were included if authors reported that they had measured QoL or well-being. All Cochrane reviews [9] published before December 2004 were hand-searched. Only trials exclusively on people with cystic fibrosis were included i.e. trials were omitted where some of the subjects had cystic fibrosis. Papers were omitted which described a study on a subset of subjects in an RCT, but secondary analyses of RCTs where the primary findings had previously been published were included. Each author undertook searches and reviews independently. A summary sheet was used to record the following: rationale for measuring QoL; choice of QoL instrument, quality of scale description and scoring methods; sample size justification; quality of summary statistics for QoL and analysis; discussion of the clinical importance of QoL findings and general methodological quality in relation to QoL

A total of 16 trials were identified. The interventions investigated were: antibiotics (4); home versus hospital administration of antibiotics (1); steroids (1); mucolytic therapies (6); exercise (3); and pancreatic enzymes (1). The trials, with patient characteristics, are summarised in Tables 1 and 2. Table 1 presents a summary of RCTs evaluating antibiotics and steroids. Table 2 summarises the RCTs evaluating mucolytic therapies, exercise and pancreatic enzymes.

\section{Review of CF trials that have measured QoL Antibiotic therapy}

One of the most important therapies for CF is antibiotics aimed at preventing, eradicating and controlling respiratory infection. Pseudomonas aeruginosa (PA) is the most prevalent infection [10], and the prognosis of chronically infected patients is considerably worse [11]. It is also known that pulmonary exacerbations have a strong negative impact on QoL in CF [12], therefore an effective antibiotic should be able to demonstrate improvements in QoL. Of the four antibiotic trials that reported measuring QoL in CF (as a secondary outcome) one evaluated tobramycin and the other three assessed azythromycin.

Tobramycin's mode of delivery is appealing to patients as it is nebulised, delivering high concentrations of the drug to the site of infection; making the treatment less complex and time-consuming than by intravenous administration. Ramsey et al. [13] conducted a placebo-controlled RCT of inhaled tobramycin and concluded that the drug improved lung function. Quittner et al. [14] reported on QoL from a secondary analysis of this work. Patients were assigned to receive either tobramycin (300 mg twice daily) or placebo for three treatment cycles, with each cycle consisting of 28 days on the drug followed by 28 days off the 
Table I: Summary of RCTs in CF measuring QoL: antibiotics and steroids

\begin{tabular}{|c|c|c|c|c|c|}
\hline Authors & Brief description & Sample & QoL scale used & $\begin{array}{l}\text { Authors' main } \\
\text { conclusion }\end{array}$ & $\begin{array}{l}\text { Authors' conclusion } \\
\text { about QoL outcome }\end{array}$ \\
\hline \multicolumn{6}{|l|}{ ANTIBIOTICS } \\
\hline $\begin{array}{l}\text { Quittner et al. [14] } \\
\text { Secondary analysis of } \\
\text { Ramsey et al. [13] }\end{array}$ & $\begin{array}{l}\text { Secondary analysis of } \\
\text { RCT. } \\
\text { Tobramycin versus } \\
\text { placebo in } 3 \text { cycles }\end{array}$ & $\begin{array}{l}\mathrm{n}=520 \text { (age }>=6 \text { years) } \\
(\mathrm{n}=499 \text { for } \mathrm{Q} \text { oL) } \\
\text { mean age } 21 \text { years } \mathrm{FEV}, \\
25 \% \text { to } 75 \%\end{array}$ & $\begin{array}{l}\text { Non-validated 3-point } \\
\text { scale (better/no change/ } \\
\text { worse) primary } \\
\text { outcome }\end{array}$ & $\begin{array}{l}\text { Tobramaycin improved } \\
\text { lung function (not } \\
\text { reported here) }\end{array}$ & $\begin{array}{l}\text { Tobramycin associated } \\
\text { with improved QoL }\end{array}$ \\
\hline Equi et al. [I7] & $\begin{array}{l}\text { Azithromycin ( } 250 \mathrm{gm} \\
\text { or } 500 \mathrm{gm} \text { dependent } \\
\text { on weight) vs placebo; } \\
\text { crossover design }\end{array}$ & $\begin{array}{l}\mathrm{n}=41 \text { (age } 8-18 \text { years) } \\
\text { median } \mathrm{FEV},=61 \% \\
\text { (range } 33 \% \text { to } 80 \% \text { ) }\end{array}$ & QWB & $\begin{array}{l}\text { Significant improvement } \\
\text { in FEV, compared with } \\
\text { placebo, but not FVC or } \\
\text { mid-expiratory flow }\end{array}$ & No difference in QoL \\
\hline Wolter et al. [18] & $\begin{array}{l}\text { Azithromycin vs } \\
\text { placebo; } 2 \text { parallel } \\
\text { groups }\end{array}$ & $\begin{array}{l}\mathrm{n}=59 \text { (age } 18-44 \text { years; } \\
\text { mean } 27.9 \text { years) mean } \\
\mathrm{FEV}_{1}=56.5 \%\end{array}$ & CRQ & $\begin{array}{l}\text { Significant difference in } \\
\mathrm{FEV}_{1} \text { and } \mathrm{FVC} \text { favouring } \\
\text { azythromycin }\end{array}$ & $\begin{array}{l}\text { Significant improvement } \\
\text { in all domains of QoL }\end{array}$ \\
\hline Saiman et al. [19] & $\begin{array}{l}\text { Azithromicyn vs } \\
\text { placebo; } 2 \text { parallel } \\
\text { groups }\end{array}$ & $\begin{array}{l}n=185 \text { (age }>=6 \text { years }) \\
(n=177 \text { for } Q \circ L) \\
\text { mean age } 20 \text { years } \approx \\
60 \% \text { had } F E V_{1}>60 \%\end{array}$ & CFQ & $\begin{array}{l}\text { Significant difference in } \\
\text { FEV }, \text { lower risk of } \\
\text { exacerbation, higher } \\
\text { weight, but more side } \\
\text { effects in treatment } \\
\text { group }\end{array}$ & $\begin{array}{l}\text { Significant difference in } \\
\text { physical functioning } \\
\text { domain only }\end{array}$ \\
\hline \multicolumn{6}{|l|}{$\begin{array}{l}\text { HOME/HOSPITAL } \\
\text { ANTIBIOTICS }\end{array}$} \\
\hline Wolter et al. [20] & $\begin{array}{l}\text { Home versus hospital } \\
\text { IVs antibiotics; } 2 \text { parallel } \\
\text { groups }\end{array}$ & $\begin{array}{l}17 \text { adolescents and } \\
\text { adults }\end{array}$ & CRQ primary outcome & $\begin{array}{l}\text { No clinical compromise } \\
\text { associated with home } \\
\text { therapy }\end{array}$ & $\begin{array}{l}\text { Home IVs fared worse } \\
\text { for fatigue and mastery, } \\
\text { but better for personal, } \\
\text { family, sleeping, eating } \\
\text { and total disruption }\end{array}$ \\
\hline \multicolumn{6}{|l|}{ STEROIDS } \\
\hline Balfour-Lynn et al. [24] & $\begin{array}{l}\text { Corticosteroids vs } \\
\text { placebo; crossover }\end{array}$ & $\begin{array}{l}\mathrm{n}=22 \text { (age } 7-17 \text { years; } \\
\text { mean } 10.3 \text { years) } \\
\text { mean } \mathrm{FEV}_{1}=64 \% \text { (range } \\
21 \% \text { to } 102 \% \text { ) }\end{array}$ & Ad hoc VAS scales & $\begin{array}{l}\text { No significant benefit in } \\
\text { any of the outcomes }\end{array}$ & $\begin{array}{l}\text { No changes in well- } \\
\text { being }\end{array}$ \\
\hline
\end{tabular}

$\mathrm{FEV}_{1}=$ forced expiratory volume in one second, expressed as percent predicted; FVC = forced vital capacity; QWB = Quality of Well-being Scale; $\mathrm{CFQ}=$ Cystic Fibrosis Questionnaire; CRQ = Chronic Disease Respiratory Questionnaire; $\approx=$ approximately. QoL is secondary outcome measure unless otherwise indicated. All authors refer to QoL in the title, abstract or paper except [24] who refer to well-being.

drug. QoL was assessed only at the end of each treatment period (28 days on the drug) using a non-validated, three point, uni-dimensional global rate of change questionnaire. Patients (or parents of some children) and physicians reported whether the patient's condition remained unchanged, improved or deteriorated. The authors reported that a greater number of patients receiving tobramycin felt better at the end of each treatment cycle. There is evidence that patients taking the drug were more likely to report an improvement in their condition after each period of treatment. However, how 'feeling better or worse' would impact on different aspects of a person's QoL is unknown and the authors themselves suggest that evaluation with CF-specific QoL scales would be beneficial. It is also unclear how many children's ratings or parental proxy ratings were included in the analysis. Pretreatment data were not collected so it is unknown what happened in the periods off treatment. Without this information, and the magnitude of all changes, it is impossible to deduce what the overall changes would have been if QoL had been measured at baseline and at 6 months.
Macrolide antibiotics are unable to kill $P A$ but it is thought that they may reduce the activity of the bacteria [15]. Azythromycin has become a focus of interest in CF because it is possible that it reduces sputum viscosity and airway adhesion of $P A[16]$. If a drug can reduce bacterial activity and inflammation, and enable sputum to be expectorated more easily, it may be expected to improve QoL. If it can also be administered orally, rather than being given intravenously or via a nebuliser, its potential impact on QoL may be considerable. Equi et al. [17] undertook a 15 month, randomised, double blind, placebo-controlled crossover trial. Patients received either azythromycin (bodyweight $<40 \mathrm{~kg}=250 \mathrm{mg}$ daily; $>40 \mathrm{~kg}$ $=500 \mathrm{mg}$ daily) or placebo for six months. This was followed by a two month washout period prior to the treatments being crossed over. Lung function was the primary outcome measure. QoL was one of several secondary outcomes and was measured using the Quality of Well Being Scale (QWB). The scale is not described in the paper but it is a utility instrument, typically administered by interview. It generates a single score by summing the scores of the three subscales: mobility, physical activity and social activity. The authors reported an improvement in $\mathrm{FEV}_{1}$ for 
Table 2: Summary of RCTs in CF measuring QoL: mucolytic therapies, exercise and pancreatic enzymes

\begin{tabular}{|c|c|c|c|c|c|}
\hline Authors & Brief description & Sample & QoL scale used & $\begin{array}{l}\text { Authors' main } \\
\text { conclusion }\end{array}$ & $\begin{array}{l}\text { Authors' conclusion } \\
\text { about QoL outcome }\end{array}$ \\
\hline \multicolumn{6}{|l|}{$\begin{array}{l}\text { MUCOLYTIC } \\
\text { THERAPIES }\end{array}$} \\
\hline Ranasinha et al. [27] & $\begin{array}{l}\text { DNase vs placebo; two } \\
\text { parallel groups }\end{array}$ & $\begin{array}{l}\mathrm{n}=71 \text { (age }=16-55 \\
\text { years) mean } F E V_{1} \approx 47 \%\end{array}$ & Ad hoc 9-item scale & $\begin{array}{l}\text { Significant improvement } \\
\text { in FEV, but not in FVC }\end{array}$ & $\begin{array}{l}\text { DNase did not improve } \\
\text { overall well-being but } \\
\text { improvements in feeling, } \\
\text { cough frequency and } \\
\text { chest congestion }\end{array}$ \\
\hline Ramsey et al. [28] & $\begin{array}{l}3 \text { doses of DNase vs } \\
\text { placebo; } 4 \text { parallel } \\
\text { groups }\end{array}$ & $\begin{array}{l}\mathrm{n}=181 \text { (age } 8-65 \\
\text { years) mean } \mathrm{FEV} \\
\text { between } 58.6 \% \text { and } \\
84.6 \% \text { for the } 4 \text { groups }\end{array}$ & Ad hoc 9-item scale & $\begin{array}{l}\text { FEV, and FVC improved } \\
\text { across all doses } \\
\text { compared with placebo }\end{array}$ & $\begin{array}{l}\text { DNase associated with } \\
\text { decreased dyspnoea and } \\
\text { improved well-being }\end{array}$ \\
\hline Fuchs et al. [29] & $\begin{array}{l}2 \text { doses of DNase vs } \\
\text { placebo; } 3 \text { parallel } \\
\text { groups }\end{array}$ & $\begin{array}{l}\mathrm{n}=968 \text { (age } 5-54 \text { years) } \\
\text { mean } \mathrm{FEV}, \approx 60 \%\end{array}$ & Ad hoc 9-item scale & $\begin{array}{l}\text { Improved lung function } \\
\text { on DNase }\end{array}$ & $\begin{array}{l}\text { Increase in general well- } \\
\text { being }\end{array}$ \\
\hline Wilmott et al. [30] & $\begin{array}{l}2.5 \mathrm{mg} \text { DNase or } \\
\text { placebo twice daily }\end{array}$ & $\begin{array}{l}\mathrm{n}=80 \text { children and } \\
\text { adults (age }>5 \text { years; } \\
\text { mean } \approx 20) \text { mean } \mathrm{FEV}, \approx \\
40 \%\end{array}$ & Ad hoc scale & $\begin{array}{l}\text { No effect of drug on } \\
\text { change in } F E V_{1} \text { or FVC }\end{array}$ & $\begin{array}{l}\text { No differences on well- } \\
\text { being scales }\end{array}$ \\
\hline Suri et al. [3I-33] & $\begin{array}{l}\text { Open crossover study } \\
\text { of DNase once daily } 2.5 \\
\mathrm{mg} \text { vs alternate day } 2.5 \\
\mathrm{mg} \text { and saline }\end{array}$ & $\begin{array}{l}\mathrm{n}=48 \text { (age } 7-17 \text { years) } \\
(\mathrm{n}=40 \text { completed } \\
\text { study) }\end{array}$ & QWB-SA & $\begin{array}{l}\text { No evidence of } \\
\text { differences between } \\
\text { active treatments; daily } \\
\text { treatment better than } \\
\text { saline for FEV }\end{array}$ & No effects \\
\hline Eng et al. [34] & $\begin{array}{l}10 \mathrm{ml} \text { of either normal } \\
\text { or hypertonic saline; } \\
\text { parallel groups }\end{array}$ & $\begin{array}{l}\mathrm{n}=58 \text { (age } 7-26 \text { years) } \\
\text { mean } \mathrm{FEV}, \approx 52 \%\end{array}$ & $\begin{array}{l}\text { Ad hoc VAS of } \\
\text { perceived change }\end{array}$ & $\begin{array}{l}\text { Significant differential } \\
\text { improvement from } \\
\text { baseline in FEV, for } \\
\text { hypertonic saline }\end{array}$ & $\begin{array}{l}\text { An improvement, but } \\
\text { group difference did not } \\
\text { reach statistical } \\
\text { significance }\end{array}$ \\
\hline \multicolumn{6}{|l|}{ EXERCISE } \\
\hline Selvadurai et al. [36] & $\begin{array}{l}\text { Comparison of aerobic/ } \\
\text { resistance training and } \\
\text { standard care; } 3 \text { parallel } \\
\text { groups }\end{array}$ & $\begin{array}{l}\mathrm{n}=66 \text { (age } 8-16 \text { years) } \\
\text { mean } \mathrm{FEV}, \approx 57 \%\end{array}$ & QWB & $\begin{array}{l}\text { Aerobic training better } \\
\text { for peak aerobic } \\
\text { capacity. Resistance } \\
\text { training better for } \\
\text { weight gain, lung } \\
\text { function and leg } \\
\text { strength }\end{array}$ & $\begin{array}{l}\text { Aerobic training } \\
\text { associated with better } \\
\text { QoL }\end{array}$ \\
\hline Klijn et al. [37] & $\begin{array}{l}\text { Anaerobic training vs } \\
\text { normal daily activity; } 2 \\
\text { parallel groups }\end{array}$ & $\begin{array}{l}\mathrm{n}=20 \text { (age 9-18 years; } \\
\text { mean I4 years) mean } \\
\mathrm{FEV}_{1}=75.2 \% \text { (exercise } \\
\text { group); } 82.1 \% \text { (control } \\
\text { group) }\end{array}$ & Dutch CFQ & $\begin{array}{l}\text { Anaerobic and aerobic } \\
\text { performance improved } \\
\text { in training group, but } \\
\text { not control group }\end{array}$ & $\begin{array}{l}\text { QoL improved in } \\
\text { training group but not in } \\
\text { control group }\end{array}$ \\
\hline Orenstein et al. [38] & $\begin{array}{l}\text { Aerobic versus upper- } \\
\text { body strength training }\end{array}$ & $\begin{array}{l}\mathrm{n}=62 \text { (age } 8-18 \text { years) } \\
\text { Analysis on } 53 \text { cases of } \\
\text { complete data }\end{array}$ & QWB & $\begin{array}{l}\text { Strength and aerobic } \\
\text { training may increase } \\
\text { upper-body strength, } \\
\text { and physical work } \\
\text { capacity }\end{array}$ & No significant effects \\
\hline \multicolumn{6}{|l|}{$\begin{array}{l}\text { PANCREATIC } \\
\text { ENZYMES }\end{array}$} \\
\hline Gan et al. [39] & $\begin{array}{l}4 \text { versus I capsule daily } \\
\text { crossover design }\end{array}$ & $\begin{array}{l}\mathrm{n}=13 \text { (age } 19-46 \text { years; } \\
\text { mean } 28 \text { years) mean } \\
\mathrm{BMI}=2 \mathrm{I}\end{array}$ & $\begin{array}{l}\text { Symptoms and general } \\
\text { well-being on } 10 \text {-point } \\
\text { scale }\end{array}$ & $\begin{array}{l}\text { No difference between } \\
\text { treatments }\end{array}$ & $\begin{array}{l}\text { No significant changes in } \\
\text { scores for well-being }\end{array}$ \\
\hline
\end{tabular}

$\mathrm{FEV}_{1}=$ forced expiratory volume in one second, expressed as percent predicted; FVC = forced vital capacity; QWB = Quality of Well-being Scale; $\mathrm{CFQ}=$ Cystic Fibrosis Questionnaire; BMI= body mass index, $\approx=$ approximately. QoL is secondary outcome measure unless otherwise indicated. All authors refer to QoL in the title, abstract or paper except [34] [39] who refer to well-being.

the drug compared with placebo. The only results given for QoL were: 'The median difference in the visual analogue score (range 0-100) for well being between the end of the azythromycin and placebo treatment periods was 0 , as was the change in the total quality of well being score'. It cannot be ascertained whether the use of a CF specific scale would have detected treatment differences.

Wolter et al. [18] reported data from a parallel design RCT comparing azythromycin with placebo. Patients took azy- thromycin $250 \mathrm{mg} /$ day or placebo for three months and were assessed at baseline and each subsequent month for lung function, weight and QoL. Quality of life was measured using the Chronic Respiratory Disease Questionnaire (CRQ). The CRQ has four subscales: fatigue, mastery, emotion and dyspnoea which can be summed to provide a total QoL score. The authors reported that treatment with azythromycin significantly reduced the rate of decline in lung function over time. Improvements in the domains of mastery, emotion, dyspnoea and total score 
were greater for those who received azythromycin. Improved fatigue scores were only seen in the azythromycin group. Although means and standard deviations of QoL scores are presented for each treatment group, there are a high proportion of missing values, and in the absence of confidence intervals it is difficult to assess the clinical importance of the results.

Similarly, Saiman et al. [19] described a parallel designed, placebo-controlled RCT to 'determine any association between azythromycin and lung function in CF'. Treatment was prescribed (bodyweight $<40 \mathrm{~kg}=250 \mathrm{mg} ;>40$ $\mathrm{kg}=500 \mathrm{mg}$ ) on three days each week for six months. QoL was one of several secondary outcome measures, and was evaluated using the USA Cystic Fibrosis Questionnaire (CFQ). Unfortunately, the scale, which is a CF specific QoL measure, was not described in the paper. The CFQ child measure is a 33 item self report instrument that includes three broad domains of QoL: physical symptoms, emotional functioning and social functioning and there are five domains that are specific to CF; body image, eating disturbances, treatment burden, respiratory symptoms and digestive symptoms. The adult version has 48 Items across 12 domains: physical, role, vitality, emotion, social, body, eating, treatment, health, weight, respiratory and digestion. The authors presented the QoL results as 'three broad factors' (physical, psychosocial, and body image) plus a total score. Presumably, these factors were an amalgamation of domains, although no explanation is provided as to how they were derived. The authors also appear to have combined the child and adult versions of the CFQ but provide no rationale or account of how this was done. A differential improvement in pulmonary function and nutritional status was reported for the azythromycin group, but for QoL the only statistically significant difference reported was for the 'physical factor'. The CFQ scales are usually scored from $0-100$. If this is the case, the observed difference of 2.7 in the 'physical factor' change score is unlikely to have clinical importance for the patient. Even a difference of 5.3, which is the extreme of the stated $95 \%$ confidence interval, is likely to be only marginally clinically important. Moreover, the small difference reported can be largely accounted for by an average deterioration of 1.9 in the placebo group. The problems of interpretation are exacerbated by a lack of baseline data on QoL scores.

\section{Home intravenous antibiotic therapy}

Home intravenous (IV) therapy is a popular form of treatment. It has the advantages of cost-saving by freeing up hospital beds and avoiding cross infection; and the patient and family are able to continue their normal activities. However, a crucial question is whether patients would adhere to their treatment sufficiently to ensure that the home and hospital environments would provide equivalent outcomes. Wolter et al. [20] conducted a parallel designed RCT of home compared with hospital IVs. The aim was 'to determine the equivalence of home and hospital care... so that if no difference was detected between the two modes of treatment, this could be stated with confidence'. Those randomised to home therapy spent 2-4 days in hospital being taught how to prepare and administer their own antibiotics. Data were obtained from 17 adolescent and adult patients for 31 admissions of respiratory exacerbation. Therapy consisted of ceftazidime, 2 g 12 hourly and tobramycin $4-6 \mathrm{mg} / \mathrm{kg}$ daily as a single bolus. QoL was the primary outcome, measured using the Chronic Respiratory Disease Questionnaire (CRQ). Patients were assessed on days 0, 10 (cessation of drug) and 21. On day 21 they were asked to score the degree of disruption to family, personal, sleeping and eating aspects of their life on a 7-point scale. The median duration of treatments was similar for both home and hospital groups. The authors reported no differences concerning dyspnoea and emotional functioning, but the fatigue, mastery and total CRQ scores were poorer for home patients. However, improved QoL was reported in the areas of personal, family, sleeping, eating and total disruption for home, compared with hospital admissions. There were no reported statistical differences in clinical outcome. QoL scores were the main outcome, but the study was only powered on the dyspnoea QoL scale. The sample size calculation, carried out during the study design, was based on 95\% power to detect 'differences of 5 or more units in the dyspnoea score'. The authors reported that 'a 5 units difference... was hypothesised as an important change'. Yet after the data had been collected it was clear that the power calculation was invalid, and the sample too small. The estimated difference in dyspnoea change scores was 2.5 , but no confidence intervals were presented. It is likely that a 95\% confidence interval for this difference would contain values greater than 5 .

\section{Anti-inflammatory therapy}

Lung inflammation can occur very early in life [21] and corticosteroids have the potential to reduce lung damage arising from inflammation. These drugs are among the most potent anti-inflammatory agents available and there is widespread prescribing of inhaled steroids in CF [22]. Oral corticosteroids are associated with several adverse effects, although the adverse effects of inhaled steroids are fewer. However, a Canadian trial was stopped prematurely because of the increased frequency of PA [23]. Because there are perceived and potential benefits and harms of steroid treatment, QoL measurement is very useful. One such trial was located. Balfour-Lynn et al. [24] conducted a double blind, placebo-controlled, randomised crossover trial in which fluticasone propionate (400 ug daily) was given as a dry powder inhaler. The drug was inhaled for six weeks with a four-week washout 
period before crossover. There were several biochemical and clinical outcome measures. At the beginning and end of each treatment period, scores for general well-being and appetite were recorded on a $10 \mathrm{~cm}$ visual analogue scale, in order to establish symptom severity. The authors concluded that there were no changes in respiratory symptoms, well-being or appetite scores. However, there is no discussion of the clinical importance of the confidence intervals in what the authors acknowledge is a small and possibly underpowered study.

\section{Mucolytic therapies}

Mucolytic agents enable respiratory secretions to be expectorated more easily. Dornase alfa (DNase) is a nebulised treatment intended for administration prior to chest physiotherapy to maximise chest clearance. Nebulised hypertonic saline is also a potential mucolytic therapy for CF. This review identified six RCTs of mucolytic therapies that measured QoL as a secondary outcome. Four of these were placebo-controlled trials of DNase, one compared DNase to hypertonic saline and one was a placebo-controlled trial of hypertonic saline.

Early studies evaluating the effective dosage, biochemical efficacy and safety of DNase in CF adults, employed a non-validated ad hoc measure of QoL $[25,26]$. This comprised five questions concerning general well-being (feeling, energy, physical activity, appetite, sleep) and four CFrelated symptoms (cough frequency, cough severity, ease of sputum expectoration and chest congestion). Patients reported these items on a five-point Likert response scale. Additionally, the magnitude of dyspnoea was rated on a visual analogue scale. Even though there were no data describing the validity, reliability or sensitivity of the measure, it was subsequently used in several studies of DNase. These included the four randomised controlled trials of DNase reported here.

Ranasinha et al. [27] conducted a double-blind, placebocontrolled RCT in which patients received either $2.5 \mathrm{mg}$ DNase twice daily or placebo for 10 days. The authors reported an improvement in lung function following DNase therapy. QoL was measured on seven occasions over the study period of 47 days (including pre-trial and follow-up). Only baseline QoL scores are reported but the authors infer that although there was no improvement in overall well-being or dyspnoea there were improvements in 'feelings', cough frequency and chest congestion. The total absence of any QoL change data makes it impossible for the reader to judge or interpret.

In a double blind placebo-controlled RCT performed by Ramsey et al. [28] children and adults were recruited. The trial consisted of four parallel groups (three different doses of DNase and placebo). The study period was 42 days with medication administered for the first ten days.Mean percentage change in lung function from baseline for each treatment group were provided at days 3, 10, 21 and 42. An improvement in lung function was observed during the administration of DNase, with values declining towards baseline following the treatment period. The authors reported a decreased perception of dyspnoea and an improved perception of well-being in the DNase groups compared to controls. Voice alteration and sore throat were more frequent among patients receiving DNase. However, QoL was not measured past day 10 so it is unclear whether QoL would have demonstrated similar trends to those of lung function. No baseline values are presented for QoL, but mean changes (from baseline to Day 10) are given for each group, without any measures of variability. There is no discussion of any possible dose-response (as is presented for $\mathrm{FEV}_{1}$ ), or of the clinical importance of the observed differences. These differences appear to be too small to be clinically important, and it is difficult to detect any consistent trends in the dose-response. Problems in interpretation are exacerbated by the lack of baseline data on QoL. It is impossible to judge if patients had scope for improvement, whether the scales were sensitive, or whether any particular dose is to be preferred with respect to QoL.

Fuchs et al. [29] conducted a double-blind, placebo-controlled RCT with three parallel groups $(2.5 \mathrm{mg}$ DNase once or twice daily and placebo). Children and adults were treated over a six-month period. Both doses of DNase resulted in slightly improved lung function. The authors report an increase in general well-being and a decrease in CF symptoms, although information is not available concerning specific symptoms of the measure (e.g. cough frequency). This was a large study and although the authors reported statistically significant differences these do not appear to be clinically important. There were ceiling effects in QoL measures at baseline: for each group the mean score was 3.9, with a maximum score of 5 (ceiling). Although the authors reported that the average change in well-being score for the once-daily group was significantly greater than for placebo, this change is extremely small, and is not replicated in the twice-daily group. There is therefore little convincing evidence about the effects of the treatments on QoL.

Wilmott et al. [30] undertook a double blind, placebocontrolled RCT with two parallel groups. Patients received either $2.5 \mathrm{mg}$ DNase or placebo twice per day for 14 days. Clinical and QoL data were recorded on days 1, 8 and 15. Similar changes in lung function occurred in both groups. The authors reported no differences between the groups for any of the well-being or CF symptom items, but they do not provide enough information to enable the reader to interpret the data. There was evidence of greater 
improvement in dyspnoea (measured on the VAS) in the treatment group. This was statistically significant at day 8 , but not at day 15, although the difference may have still been clinically important at day 15 . This possible treatment effect was not reported in the QoL results, where, for all scales (including dyspnoea at different levels of activity) they report 'no difference between the groups'.

DNase is a comparatively expensive treatment for CF and not all patients can benefit from it. Hypertonic saline is an inexpensive potential alternative. A comparison of DNase and hypertonic saline was undertaken by Suri et al [[3133] - publications of same trial]. They conducted an open, randomised crossover trial. Children were randomised to once daily DNase $(2.5 \mathrm{mg})$, alternate day DNase $(2.5 \mathrm{mg})$ or twice daily $5 \mathrm{~mL} 7 \%$ hypertonic saline in blocks of 12 weeks' duration with a two week washout period between treatments. In addition to the efficacy of the three treatments the study aimed to compare cost-effectiveness and therefore a utility measure of QoL, the Quality of Wellbeing Scale-Self Administered (QWB-SA), was chosen. The QWB-SA contains five domains: acute and chronic generic symptoms, self care, mobility, physical activity and performance of usual activities. These domains are combined to produce a well-being score of between 0 (death) and 1 (symptom-free full function). Parent and child completed the questionnaire together. The authors reported no difference in improved lung function between daily and alternate day DNase (16\% and 14\% improvement in $\mathrm{FEV}_{1} \%$ respectively). A mean $\mathrm{FEV}_{1} \%$ predicted improvement of only $3 \%$ was observed for the hypertonic saline condition and a statistically significant difference was reported between daily DNase and hypertonic saline. There were no significant changes from baseline for any treatment on the QWB-SA scale; neither were there differences between the treatment change scores. The trial was not powered for QoL and in one paper [31] the authors included confidence intervals. An improvement in reported well-being may be expected to accompany these relatively large changes in lung function in the DNase groups, yet the authors do not discuss possible reasons for these negative findings.

Eng et al. [34] conducted an open-label, placebo-controlled, parallel trial. Patients were randomly allocated to receive $10 \mathrm{ml}$ of either normal saline $(0.9 \% \mathrm{NaCl})$ or hypertonic saline $(6.0 \% \mathrm{NaCl})$ twice daily (nebulised prior to physiotherapy) for two weeks. Change in lung function was the primary outcome and patient-perceived CF related symptoms were a secondary outcome. Patients rated perceived change of dyspnoea, fatigue, appetite, exercise tolerance, sleep and general well-being on a 10 $\mathrm{cm}$ visual analogue scale (VAS) on days 14 and 28. They also rated the effectiveness of sputum clearance on a similar VAS based on their diary information. Hypertonic saline improved lung function (at day 14) compared with normal saline; the mean increase in $\mathrm{FEV}_{1} \%$ predicted from baseline was $15 \%$ for the hypertonic saline compared with $2.8 \%$ for normal saline. The authors reported that the administration of hypertonic saline significantly improved exercise and the quality of sleep. For the other symptoms and general well-being there were no statistically significant differences between the groups. However, it is unlikely that the study was adequately powered for symptoms and well-being scores. While some of the estimated differences may only appear marginally important, it is probable the $95 \%$ confidence intervals for most of the symptoms and well-being scores would contain clinically important values. Given this problem, together with a total lack of information about QoL and symptoms at baseline, the QoL results are inconclusive.

\section{Exercise}

Lung function and exercise tolerance decrease as CF disease progresses. Exercise training aims to preserve and improve fitness levels and enable CF patients to perform everyday activities. Patients with high levels of aerobic fitness have better survival than those with low fitness levels [35]. Aerobic training aims to improve cardiovascular function whereas anaerobic or resistance training aims to improve muscle strength. Three RCTs of exercise measuring QoL as a secondary outcome were located.

Selvadurai et al. [36] conducted an RCT to compare aerobic and resistance training. Children, admitted to hospital for a pulmonary exacerbation, were randomised to one of three parallel groups; aerobic training, resistance training and a control group. The mean duration of hospitalisation was around 19 days for each group. The exercise groups received five training sessions each week. All groups received in-patient standard care - intravenous antibiotics, chest physiotherapy and nutritional supplements. Peak aerobic capacity and lung function appear to be primary outcomes, measured on admission to hospital and at discharge. Quality of life, measured by the QWB scale, was assessed at baseline and one month following discharge. The authors do not describe the scale, its scoring method, or what the tabulated values represent. They report that aerobic training was associated with better peak aerobic capacity, activity levels and QoL, whereas children who received resistance training had better weight gain, lung function and leg strength.

Klijn et al. [37] investigated the effects of anaerobic training in non-hospitalised children who were randomly assigned to either a training group or control group. The exercise group trained for 30-45 minutes, twice each week for twelve weeks. There were several clinical and physiological outcomes. QoL was measured by the Dutch version of the Cystic Fibrosis Questionnaire (CFQ). A 47 
item teen/adult scale and a 35 item child scale of the CFQ were employed but there was no description of the psychometric properties of this recently-translated scale. The domains of the scales were not described and neither was the instrument's scoring system. All outcome measures were evaluated at baseline, at the end of the training period and at 12 weeks' follow-up. The authors reported that by the end of the training period the children in the exercise group had improved their anaerobic and aerobic performance and QoL. At twelve weeks follow-up anaerobic performance and QoL remained higher than pre-training values. However, for QoL scores there are no direct statistical tests comparing the groups, and no confidence intervals. It also appears that data from the CFQ child and teen/adult scales were incorporated into the same analysis and it is unclear how this was achieved. There was inadequate reporting of summary statistics to enable the reader to interpret the findings, and selective reporting of QoL data. The CFQ scales consist of numerous domains but only the physical functioning domain was statistically significant. Even so, the authors conclude that 'anaerobic training has measurable effects on QoL'. Furthermore, the interpretation of the physical function data is unreliable because baseline imbalances in this score were not considered (training group mean 70.3; control group mean 83.2).

Orenstein et al. [38] conducted a one-year randomised trial to compare the effects of a home-based, semi-supervised, upper-body strength training regimen with a similarly structured aerobic training regimen. Sixty-two children participated in the trial although analysis was undertaken on 53 completed cases. Participants in both exercise conditions were visited at home once per week for the first eight weeks then monthly for the remainder of the study. All patients were encouraged to exercise at least three times per week for a year. Aerobic fitness, pulmonary function, strength and QoL were measured at baseline, 6 and 12 months. QoL was measured using the interview format of the QWB scale: for children younger than 12 years a parent responded. The authors concluded that strength and aerobic training may increase upper body strength and that both types of training may increase physical work capacity. There were no statistically significant differences for either within or between group analyses for QoL. Interpretation of results rests on p-values, with no discussion of clinical importance, although the reported differences in total well-being score appear to be too small to be of clinical importance.

\section{Pancreatic enzyme therapy}

The majority of CF patients develop pancreatic insufficiency which leads to the maldigestion of dietary lipid, protein and carbohydrate. Pancreatic enzyme replacement therapy is used to manage maldigestion with patients taking numerous capsules each day. Gan et al. [39] conducted a double-blind, randomised crossover trial to compare a high lipase pancreatic enzyme preparation (Pancrease-HL) with regular Pancrease capsules. The rationale was that if the same strength of pancrease could be put into 1 capsule instead of 4 , adherence to treatment may improve. Thirteen adults participated in two study periods of 14 days. During each period patients took 5 capsules 3 times per day; either 4 of Pancrease and 1 of placebo or 1 of Pancrease-HL and 4 placebo. The primary outcome measures appear to be mean fat and nitrogen excretion. General well-being was measured daily on a ten point scale. The authors reported no differences between the groups for any outcome. It is unclear whether the scores presented are baseline or change scores, or if the daily ratings were combined in some way to calculate the well-being scores. The authors' conclusion is that one capsule of the new preparation appears to be 'equivalent' to four capsules of the regular preparation, which suggests that the design should have been an equivalence study. However, in the absence of a clear hypothesis for the study, or a sample size calculation it is difficult to be sure. Whatever the hypothesis, the possible lack of power means that confidence intervals are essential for valid interpretation of results.

\section{Discussion of QoL data from CF trials}

The value of the evidence from a trial depends on the quality of its design. Much of the data presented here was difficult to interpret. There are several reasons for this, and these are presented in this discussion.

\section{Choice of QoL measure}

Only a few papers provided a rationale for measuring QoL $[14,20,30,31]$ or a rationale for the choice of QoL instrument $[18,20,30,31]$. A variety of scales, reported to measure QoL, were employed: a uni-dimensional global rate of change questionnaire [14],'ad hoc' CF rating scales $[24,27-30,34,39]$, the Quality of Well-being Scale $[17,31,36,38]$, the Chronic Respiratory Disease Questionnaire $[18,20]$, and the American [19] and Dutch [37] versions of the Cystic Fibrosis Questionnaire. The fact that a scale has been previously used on a CF population does not mean that it has been appropriately validated for use in CF studies. Apart from CF specific QoL instruments $[40,41]$ only the SF-36 $[42,43]$ and the Chronic Respiratory Disease Questionnaire (CRQ) [44] have undergone appropriate psychometric testing in CF. A chosen scale should be relevant to the participants, disease and intervention. It is also important that a scale is sensitive to change, otherwise a negative finding could be an artefact of the insensitivity of the scale and not of the real effect of the treatment on QoL. It may be more ethical not to measure QoL at all than to use an inappropriate scale which could give misleading results. 


\section{Quality of reported data}

In order for readers to assess the importance of RCT findings, it is essential to have adequate descriptions of the outcomes and data. CONSORT recommends: 'Authors should give full details of how the primary and secondary outcomes were measured' and 'for each primary and secondary outcome, a summary of results for each group and the estimated effect size and its precision (e.g. 95\% confidence interval)'.

\section{Description of scale and scoring methods}

Some papers gave neither a full description of the scale nor an explanation of the scoring method $[17,19,30,36,37,39]$. Several studies included children but it is not always clear whether the child, parent or a combination responded. Irrespective of the difficulties encountered with the interpretation of a combination of patient and patient proxy data, it is useful to know from whom the data have been obtained. A comprehensive description of the scale and scoring methods is particularly important in cases where scales have been merged across child and adult versions [19,37] or the scale transformed [38]. One paper stated that two scales with different numbers of items and domains had been combined but did not justify this or describe how it had been done [37]. While the statistical power is likely to be increased by such pooling, there is no guarantee that it is clinically meaningful.

\section{Baseline data}

QoL outcomes are often secondary, and a RCT may not have been powered on them. It is therefore important that adequate summary information is provided. A table of baseline characteristics, by treatment group, allows readers to judge the success of the randomisation. There may be clinically important baseline differences between the groups, or ceiling or floor effects. In several papers it was impossible to assess the validity of the conclusions, as there was incomplete summary information about QoL baseline values $[17,19,20,28,34,37]$.

\section{Statistical versus clinical significance}

It is important to distinguish between statistical significance and clinical significance. This is addressed in the CONSORT statement as follows: 'The difference between statistical significance and clinical importance should always be borne in mind. Authors should particularly avoid the common error of interpreting a non-significant result as indicating equivalence of interventions. The confidence interval provides valuable insight into whether the trial result is compatible with a clinically important effect, regardless of the p-value'. Most statistical tests will give a confidence interval for the difference, as well as a p-value. A 95\% confidence interval gives a range of values, which we can be $95 \%$ sure contains the true difference. When the p-value is greater than 0.05 , and the $95 \%$ confidence interval contains no values of any clinical importance, it is reasonable to conclude that any real difference between treatments is too small to be of any interest. If a study is too small then the observed difference may be too small to reach statistical significance, even in the presence of a genuine difference in treatments. Conversely, in large studies, small changes in both $\mathrm{FEV}_{1}$ and QoL scores may be statistically significant as determined by a p-value but the observed differences may be too small to be clinically relevant. In this review there was a tendency for QoL results to be interpreted in terms of statistical significance. Of the two papers where QoL was the main outcome, Quittner [14] provided a full description of the data, whereas Wolter [20] gave no confidence intervals or measures of variability. Only three studies in which QoL was a secondary outcome reported confidence intervals $[19,24,31]$ even though the studies were not powered on the QoL outcome. Most reported standard deviations or standard errors but three gave no description of variability $[17,27,39]$. Overall, there was little or no discussion of QoL results when they were statistically non-significant. Neither was there adequate discussion of the relationship between QoL results and those for the primary outcomes.

\section{Types of trials, sample size and QoL Superiority trials}

It is important that an RCT has adequate power. The majority of RCTs are superiority trials, where the aim is to test whether one treatment is better than another (or than placebo). CONSORT states: 'Ideally a study should be large enough to have a high probability (power) of detecting a statistically significant or clinically important difference of a given size if such a difference exists'... 'Reports of studies with small samples frequently include the erroneous conclusion that the intervention groups do not differ, when too few patients were studied to make such a claim'. In this review some papers did not report a formal sample size calculation for any outcome $[24,28,38,39]$. One study [24] reported a retrospective power calculation based on the observed data, which is of little value [8]. No study had an a priori sample size calculation for QoL when this was a secondary outcome.

\section{Crossover trials}

In some circumstances using a crossover design can alleviate the problem of requiring a large sample. Four crossover trials were located $[17,24,31,39]$. Crossover trials are useful where the effect of a treatment can be switched on and off, and it is ethical to do this. When feasible they can be more efficient than parallel-group designs because each participant acts as his/her own control and a smaller sample is required for the same statistical power. However, although a great deal might be known about the pharmacological effect of a drug in the body and its con- 
sequent effect on lung function, much less is understood about possible carryover effects on QoL. This is potentially compounded in studies where there are more than two treatment periods.

\section{Non-inferiority trials}

There are instances in which the aim is not to demonstrate superiority of one treatment over another, but to show therapeutic equivalence i.e. that one treatment is not inferior to another. The methods used for superiority trials are then of no use; failure to find a statistically significant difference is not the same as establishing equivalence. In fact, it is impossible to show 'exact' equivalence, so researchers have to define the range of values, near zero, that are of no clinical interest. This value of 'no difference' must, logically, be less than the minimal clinically important difference (MCID). For example, if the MCID for a QoL scale is 10 points a difference of 3 units between groups would probably be classed as 'equivalent'; it may be less clear how to view a difference of 7 units. This is a clinical decision, not a statistical one, and the values need to be established before the sample size calculation is done. For the two cases in this review where equivalence designs were apparently employed [20,39] there was either a lack of precision in the aim of the trial, or an inappropriate analysis. In the one trial where QoL was the primary outcome [20], the sample size calculation was not presented in terms of equivalence, and was revised after data were collected. This resulted in a retrospective adjustment to the definition of what had been deemed to be a clinically important difference. There was no sample size calculation in the other study [39].

\section{Missing values}

Many RCTs suffer problems with missing values. These can be sporadic (e.g. where a patient misses an appointment or omits to return one questionnaire) or because of dropout, where data are completely missing after a certain time. This can be a common problem in QoL measurement and researchers have to decide how to deal with incomplete data. One way is to omit cases with missing values. If values are missing 'completely at random', then analysis on the complete data can be valid, although it is against the principle of 'intention to treat'. However, missingness is more often related to a change in condition [45]. In practice it is very difficult to be sure that values are missing completely at random, simply because the values are unknown.

The implications of missing data are potentially serious if about $15 \%$ or more of the values are missing, or if there are different patterns of missingness between treatment groups. When there is a significant amount of missing data it is highly desirable to check the sensitivity of the results by using more than one statistical method. There are a variety of methods that can handle incomplete data. Different methods give potentially different results, because they make different assumptions about the reasons for missingness. Some methods are relatively simple (e.g. use the last recorded value) but p-values and confidence intervals should really be adjusted. Methods like ttests and repeated measures ANOVA require complete data. However, there are more sophisticated methods like Generalised Estimating Equations (GEEs) that can be used to analyse longitudinal data with different numbers of observations per participant. Nonetheless, the fact that the analysis is possible does not mean that it is valid. Researchers should compare participants with and without missing data to check for potential systematic differences. Most papers reported missing observations for the QoL outcomes, some of which were substantial $[18,31,38]$. Only Suri [31] gave any description of dropouts and checked that they were not the most severely affected participants. Orenstein [38] omitted dropouts from the analysis because of potential bias, but did not explore the nature of the dropouts and the possible bias resulting from their exclusion. Some researchers used GEEs for their analysis $[18,31,38]$ but gave incomplete details of the chosen options.

\section{Conclusion}

Authors tend to provide definite statements about QoL, but no trial in this review provided conclusive data. Even well-designed clinical trials can be difficult to manage, and high-quality reporting is essential. In the papers in this review the treatments and patient characteristics were generally well described. Difficulties arose when QoL scales were not described and summary information was not provided. Journal editors place word restrictions on papers so full descriptions of all secondary outcomes are not always possible. However, interpretation was further confounded when the emphasis was purely based on statistical significance ignoring clinical relevance. Although the CONSORT statement is an excellent guide for RCTs, it was not available when some of the trials were reported, and it does not specifically address QoL assessment and psychometric validity [46]. Properly validated diseasespecific QoL measures are most appropriate for the evaluation of CF therapies as they include the relevant items that are likely to be sensitive to change [47]. Without suitable guidelines it is difficult for authors to employ QoL scales appropriately. This review highlights many of the pitfalls of QoL measurement in CF clinical trials and provides constructive information concerning QoL in trial design and the reporting of QoL data.

\section{Authors' contributions}

Both authors planned the study, independently located and reviewed the trials, drafted the paper and agreed the final version 


\section{References}

I. Kerem BS, Rommens JM, Buchanan JA, Markiewicz D, Cox TK, Chakravarti A, Buchwald M, Tsui LC: Identification of the cystic fibrosis gene: genetic analysis. Science 1989, 245:1073-1080.

2. Welsh MJ: Electrolyte transport by airway epithelia. Physiol Rev 1990, 67: I| 43-1 I64

3. Dodge JA, Morison S, Lewis PA, Coles EC, Geddes D, Russell G, Littlewood JM, Scott MT: Incidence, population and survival of cystic fibrosis in the UK (1968-95). Arch Dis Child 1997, 77:493-496.

4. Cystic Fibrosis Patients Registry: 1995 Annual Data Report Bethesda, Maryland; 1996.

5. Elborn JS, Britton JR, Shale DJ: Cystic fibrosis: current survival and population predictions until the year 2000. Thorax 1991, 46:88I-885.

6. Kerem E, Corey M, Gold R, Levinson H: Pulmonary function and clinical course in patients with cystic fibrosis after pulmonary colonisation with Pseudomonas aeruginosa. J Pediatr 1990, I 16:7|4-719.

7. Pamukcu A, Bush A, Buchdahl R: Effects of Pseudomonas aeruginosa colonisation on lung function and anthropomorphic variables in children with cystic fibrosis. Pediatr Pulmonol 1995, 19:10-15.

8. Moher D, Schulz KF, Altman D, CONSORT Group (Consolidated Standards of Reporting Trials): The CONSORT statement: revised recommendations for improving the quality of reports of parallel-group randomized trials. JAMA 200I, 285:1987-1991] [http://www.consort-statement.org/revisedstate ment.htm].

9. The Cochrane Database of Systematic Reviews: The Cochrane Collaboration. [http://www.thecochranelibrary.com]. Published by John Wiley \& Sons, Ltd

10. Doring G, Conway SP, Heijerman HGM, Hodson M, Hoiby N, Smyth A, Touw DJ: Antibiotic therapy against Pseudomonas aeruginosa in cystic fibrosis: A European Consensus. Eur Respir J 2000, 1 6:749-767.

II. Cystic Fibrosis Foundation: Patient Registry 1996 Annual Data Report Bethesda, Maryland; 1997.

12. Britto MT, Kotagal UR, Hornung RW, Atherton HD, Tsevat J, Wilmott RW: Impact of recent pulmonary exacerbations on quality of life in patients with cystic fibrosis. Chest 2002, | 2 1:64-72.

13. Ramsey BW, Pepe MS, Quan JM, Otto KL, Montgomery AB, WilliamsWarren J, Vasiljev K, Borowitz D, Bowman CM, Marshall BC, Marshall $S$, Smith AL: Intermittent administration of inhaled tobramycin in patients with cystic fibrosis. N Engl J Med I999, 340:23-30.

14. Quittner AL, Buu A: Effects of tobramycin solution for inhalation on global ratings of quality of life in patients with cystic fibrosis and Pseudomonas aeruginosa infection. Pediatr Pulmonol 2002, 33:269-276.

15. Nagai H, Shishido H, Yoneda R, Yamaguchi E, Tamura A, Kurashima A: Long-term low-dose administration of erythromycin to patients with diffuse panbronchiolitis. Respiration 1991, 58:145-|49.

16. Peckham DG: Macrolide antibiotics and cystic fibrosis. Thorax 2002, 57:189-190.

17. Equi A, Balfour-Lynn IM, Bush A, Rosenthal M: Long term azithromycin in children with cystic fibrosis: a randomised, placebocontrolled crossover trial. Lancet 2002, 360:978-984.

18. Wolter J, Seeney S, Bell S, Bowler S, Masel P, McCormack J: Effect of long term treatment with azithromycin on disease parameters in cystic fibrosis: a randomised trial. Thorax 2002, 57:212-216.

19. Saiman L, Marshall BC, Mayer-Hamblett N, Burns JL, Quittner AL, Cibene DA, Coquillette S, Fieberg AY, Accurso FJ, Campbell PW, for the Macrolide Study Group: Azithromycin in Patients with Cystic Fibrosis Chronically Infected with Pseudomonas aeruginosa: A Randomized Controlled Trial. JAMA 2003, 290: $1749-56$

20. Wolter JM, Bowler SD, Nolan PJ, McCormack JG: Home intravenous therapy in cystic fibrosis: $A$ prospective randomized trial examining clinical, quality of life and cost aspects. Eur Respir J 1997, 10:896-900.

21. Kahn TZ, Wagner JS, Bost T, Martinez J, Accurso FJ, Riches DWH: Early pulmonary inflammation in infants with cystic fibrosis. Am J Respir Crit Care Med 1995, I 5 I:1075-1082.
22. Balfour-Lynn IM, Dezateux C: Corticosteroids and ibuprofen in cystic fibrosis. Thorax 1999, 54:657-657.

23. Schmidt J, Davidson AGF, Seear M, Wong LTK, Peacock D, Gravelle A, Menon K, Cimolai N, Speert DP: Is the acquisition of pseudomonads in cystic fibrosis patients increased by use of inhaled corticosteroids? Unexpected results from a double blind placebo controlled study [abstract]. Pediatr Pulmonol I997, I 4:293-294.

24. Balfour-Lynn I, Klein NJ, Dinwiddie R: Randomised controlled trial of inhaled corticosteroids (fluticasone propionate) in cystic fibrosis. Arch Dis Child 1997, 77:124-I30.

25. Aitken ML, Burke W, McDonald G, Shak S, Montgomery AB, Smith A Recombinant human DNase inhalation in subjects and patients with cystic fibrosis. A Phase I study. JAMA 1992, 267:1947-1951.

26. Hubbard RC, McElvaney NG, Birrer P, Shak S, Robinson WW, Jolley C, Wu M, Chernick MS, Crystal RG: A preliminary study of aerosolized recombinant human deoxyribonuclease I in the treatment of cystic fibrosis. N Engl J Med 1992, 326:8।2-8I5.

27. Ranasinha C, Assoufi B, Shak S, Christiansen D, Fuchs H, Empey D, Geddes D, Hodson M: Efficacy and Safety of Short-Term Administration of Aerosolized Recombinant Human DnaseI in Adults with Stable Stage Cystic- Fibrosis. Lancet 1993, 342:199-202.

28. Ramsey BW, Astley SJ, Aitken ML, Burke W, Colin AA, Dorkin HL, Eisenberg JD, Gibson RL, Harwood IR, Schidlow DV, Wilmott RW, Wohl ME, Meyerson LJ, Shak S, Fuchs H, Smith AL: Efficacy and safety of short-term administration of aerosolized recombinant human deoxyribonuclease in patients with cystic fibrosis. Am Rev Respir Dis 1993, I 48: |45-I5I.

29. Fuchs HJ, Borowitz DS, Christiansen DH, Morris EM, Nash ML, Ramsey BW, Rosenstein BJ, Smith AL, Wohl ME: Effect of Aerosolized Recombinant Human Dnase on Exacerbations of Respiratory Symptoms and on Pulmonary-Function in Patients with Cystic-Fibrosis. N Engl J Med 1994, 33 I:637-642.

30. Wilmott RW, Amin RS, Colin AA, DeVault A, Dozor AJ, Eigen $H$, Johnson C, Lester LA, McCoy K, Mckean LP, Moss R, Nash ML, Jue CP, Regelmann W, Stokes DC, Fuchs HJ: Aerosolized recombinant human DNase in hospitalized cystic fibrosis patients with acute pulmonary exacerbations. Am J Respir Crit Care Med 1996, 153:1914-1917.

31. Suri R, Wallis C, Bush A, Thompson S, Normand C, Flather M, Grieve $R$, Metcalfe $C$, Lees $B$ : A comparative study of hypertonic saline, daily and alternate-day rhDNase in children with cystic fibrosis. Health Technol Assess 2002, 6: 1-60.

32. Suri R, Metcalfe C, Lees B, Grieve R, Flather M, Normand C, Thompson S, Bush A, Wallis C: Comparison of hypertonic saline and alternate-day or daily recombinant human deoxyribonuclease in children with cystic fibrosis: a randomised trial. Lancet 200I, 358:1316-1321.

33. Suri R, Grieve R, Normand C, Metcalfe C, Thompson S, Wallis C, Bush A: Effects of hypertonic saline, alternate day and daily rhDNase on healthcare use, costs and outcomes in children with cystic fibrosis. Thorax 2002, 57:84I-846

34. Eng PA, Morton J, Douglass JA, Riedler J, Wilson J, Robertson CF: Short-term efficacy of ultrasonically nebulized hypertonic saline in cystic fibrosis. Pediatr Pulmonol 1996, 21 :77-83.

35. Nixon PA, Orenstein DM, Kelsey SF, Doershuk CF: The prognostic value of exercise testing in patients with cystic fibrosis. $N$ Engl J Med 1992, 327:1785-1788.

36. Selvadurai HC, Blimkie C], Meyers N, Mellis CM, Cooper PJ, van Asperen PP: Randomized controlled study of in-hospital exercise training programs in children with cystic fibrosis. Pediatr Pulmonol 2002, 33:194-200.

37. Klijn PHC, Oudshoorn A, van der Ent CK, van der Net J, Kimpen JL, Helders PJM: Effects of anaerobic training in children with cystic fibrosis: A randomized controlled study. Chest 2004, I 25: | 299- I 305

38. Orenstein DM, Hovell MF, Mulvihill M, Keating KK, Hofstetter R, Kelsey S, Morris K, Nixon PA: Strength vs aerobic training in children with cystic fibrosis - A randomized controlled trial. Chest 2004, 1 26: | 204-1214.

39. Gan KH, Heijerman HGM, Geus WP, Bakker W, Lamers CBHW: Comparison of A High Lipase Pancreatic-Enzyme Extract with A Regular Pancreatin Preparation in Adult CysticFibrosis Patients. Aliment Pharmacol Ther 1994, 8:603-607. 
40. Gee L, Abbott J, Conway S, Etherington C, Webb AK: Development of a disease specific health related quality of life measure for adults and adolescents with cystic fibrosis. Thorax 2000 , 55:946-954.

41. Modi AC, Quittner AL: Validation of a disease specific measure of health related quality of life for children with cystic fibrosis. J Pediatr Psychol 2003, 28:535-545.

42. Gee L, Abbott J, Conway S, Etherington C, Webb AK: Validation of the SF-36 for the assessment of health related quality of life in adults with cystic fibrosis. J Cyst Fibros 2002, I: | 37- I45.

43. Goldbeck L, Schmitz TG: Comparison of three generic questionnaires measuring quality of life in adolescents and adults with cystic fibrosis: The 36-item short form health survey, the quality of life profile for chronic diseases, and the questions on life satisfaction. Qual Life Res 200 I, 10:23-36.

44. Bradley J, Dempster M, Wallace E, Elborn S: The adaptation of a quality of life questionnaire for routine use in clinical practice: The CRQ in cystic fibrosis. Qual Life Res 1999, 8:65-7I.

45. Fayers PM, Machin D: Quality of Life Assessment, Analysis and Interpretation John Wiley and Sons; 2000:235.

46. Clarke SA, Eiser $\mathrm{C}$ : The measurement of health-related quality of life (QOL) in paediatric clinical trials: a systematic review. Health Qual Life Outcomes 2004, 2:66 [http://www.hqlo.com/content/ 2/1/66].

47. Abbott J, Gee L: Quality of life in children and adolescents with cystic fibrosis: implications for optimising treatments and clinical trial design. Paediatr Drugs 2003, 5:4I-56.

Publish with Bio Med Central and every scientist can read your work free of charge

"BioMed Central will be the most significant development for disseminating the results of biomedical research in our lifetime. "

Sir Paul Nurse, Cancer Research UK

Your research papers will be:

- available free of charge to the entire biomedical community

- peer reviewed and published immediately upon acceptance

- cited in PubMed and archived on PubMed Central

- yours - you keep the copyright

Submit your manuscript here:

http://www.biomedcentral.com/info/publishing_adv.asp
BiolMedcentral 